\title{
A PERPETUAÇÃO DE MITOS NO PENSAMENTO GEOGRÁFICO: A IDÉIA DAS INFLUÊNCIAS AMBIENTAIS E A FALSA DICOTOMIA DETERMINISMO/POSSIBILISMO
}

\author{
PERPETUATING MYTHS IN THE GEOGRAPHICAL THOUGHT: \\ THE IDEA OF ENVIRONMENTAL INFLUENCES AND THE FALSE \\ DICHOTOMY DETERMINISM/POSSIBILISM
}

\section{LA PERPETUACIÓN DE MITOS EN EL PENSAMIENTO GEOGRÁFICO: LA IDEA DE LAS INFLUENCIAS AMBIENTALES Y LA FALSA DICOTOMÍA DETERMINISMO/POSSIBILISMO}

\section{Ilton Jardim de Carvalho Junior}

Doutor em Geografia Física pela Universidade de São Paulo. Prof. Dr. Adjunto Universidade Estadual de Maringá (UEM), DGE, Bloco J-12, sala 17. Av. Colombo, 5.790. Jd. Universitário. CEP: 87020-900 Maringá-Paraná-Brasil.e-mail: iltongeo@hotmail.com

\section{Aparecido Pires de Moraes Sobrinho}

Mestre em Geografia pela Universidade Estadual de Maringá. Professor na Secretaria de Educação do Paraná, núcleo Maringá. Correspondência: PGE, Bloco H-12, sala 18. Av. Colombo, 5.790. Jd. Universitário. CEP: 87020-900 Maringá-Paraná-Brasil. e-mail:aparecido16@yahoo.com.br

\section{RESUMO}

O objetivo deste artigo é desfazer alguns mal-entendidos na história do pensamento geográfico, enfatizando a falsa dualidade determinismo-possibilismo. Em nossa formação acadêmica, às vezes ouvimos ou lemos informações que caracterizam o pensamento geográfico do século XIX como uma banal querela entre a escola determinista alemã e a escola possibilista francesa. As críticas trocadas raramente tocaram nas principais fraquezas de ambas as teorias, e por vezes resvalaram para deboches improdutivos e críticas superficiais. Críticas mais perspicazes emergiram na década de 50, 60 e 70, quando alguns autores como Lewthwaite, Martin, Speth, Spate, Peet e Montefiori, escreveram artigos para defender suas posições e suscitar novas nuances nas críticas ao possibilismo e ao determinismo. O determinismo ambiental não deve ser concebido como um rótulo dado a uma teoria que advoga determinação absoluta e única de fatores ambientais. A exacerbação da dualidade determinismopossibilismo só ocorreu por rixas acadêmicas e contendas político-ideológicas, e também porque se fixou em demasia nos seus conceitos-modelo, que não passam de abstrações que fazem sentido apenas em um contexto metafísico. Ao longo do século $\mathrm{XX}$, o possibilismo foi esvaziando-se de sentido e o determinismo foi declarado morto, entrando em cena o probabilismo, formulado na Geografia por Spate. Em não havendo 
mais discussões sérias acerca de um tema tão fundamental da Geografia e da ciência, mitos, fantasias, dúvidas e inseguranças foram fermentando no coração da história do pensamento geográfico.

Palavras-chave: história ambiental, falsa dualidade; determinismo; possibilismo; pensamento geográfico, mitos.

\section{ABSTRACT}

The purpose of this article is to enlighten some misunderstandings in the history of geographical thought, emphasizing the false duality possibilism/determinism. In our academic education, sometimes we hear or read of geographical thought in the nineteenth century as a merely trivial quarrel between the "German school of determinism" and the "French school of possibilism". The criticisms launched could barely mention the main weaknesses of both theories, and sometimes slipped into unproductive mockery and superficial criticism. Most of the insightful criticism emerged in the 50s, 60s and 70s, when some authors as Lewthwaite, Martin, Speth, Spate, Peet and Montefiori, wrote articles to defend their positions and show new nuances in the criticism about possibilism and determinism. The environmental determinism should not be conceived as a label given to a theory that advocates absolute and unique determination of environmental factors on man. Exacerbation of the duality determinism/possibilism occurred by the influence of academic feuds and politicalideological strife, and also because they set some concepts in their model which are but abstractions that make sense only in a metaphysical context. Throughout the twentieth century, possibilism has been dismissed and determinism was declared dead, giving way to the idea of "probabilism", brought to Geography by Spate. In the absence of more serious discussions about such a fundamental theme of Geography and Science in the last decades, myths, fantasies, doubts and misconceptions have been brewing in the heart of the history of geographical thought.

Keywords: environmental history, false duality; determinism; possibilism; geographical thought, myths. 


\section{RESUMEN}

El propósito de este artículo es disipar algunos malentendidos en la historia del pensamiento geográfico, enfatizando la falsa dualidad posibilismo-determinismo. En nuestra formación académica, a veces escuchamos o leemos informaciones que caracterizam el pensamiento geográfico del siglo XIX, como una disputa trivial entre la escuela determinista alemán y la escuela posibilista francesa. Las críticas parecen haber raramente tocado las principales debilidades de las dos teorías, as veces deslizado en abucheos improductivos y crítica superficial. La mayoría de la crítica perspicaz surgió en los años 50, 60 y 70, cuando algunos autores como Lewthwaite, Martin, Speth, Spate, Peet y Montefiori, escribieron artículos para defender sus posiciones y plantear nuevos matices en el la critica al posibilismo crítico y al determinismo. El determinismo ambiental no debe ser concebido como un nombre dado a una teoría que aboga determiniacion absoluta de factores ambientales. La exacerbación de la referida dualidad sólo ocurrió por rencillas académicas y lucha político-ideológica, y también porque estas criticas enfatizaran demasiadamente en conceptos y modelos que son sólo abstracciones que sólo tienen sentido en un contexto metafísico. A lo largo del siglo XX, el posibilismo fue vaciándose de sentido y el determinismo fue declarado muerto, entrando en escena el probabilismo formulado en la Geografía por Spate. Por culpa de las criticas equivocadas sobre un tema tan fundamental de la geografía y la ciencia, mitos, fantasías, dudas e inseguridades se gestaran en el corazón de la historia del pensamiento geográfico.

Palavras clave: historia ambiental, falsa dualidad; possibilismo; determinismo; pensamiento geográfico, mitos.

\section{INTRODUÇÃO}

"Nomear, como se sabe, é fazer ver, é criar, levar à existência".

Pierre Bourdieu

Em nossa formação acadêmica, às vezes ouvimos ou lemos informações que caracterizam o pensamento geográfico do século XIX como uma banal querela entre a escola determinista alemã e a escola possibilista francesa. Não pode haver equívoco maior. Somos bombardeados cotidianamente com rótulos, pais e avós da geografia, escolas, correntes (que nos amarram muito!), e enxurradas de "ismos" que, desde nosso berço, nos ensinam a odiar ou a desprezar.

Em consonância com a Filosofia e com a honestidade científica, devemos exercitar o questionamento e dar vazão à nossa curiosidade, para então buscar nas obras originais dos autores criticados, o que realmente está em questão, o que realmente disseram esses autores, sem descontextualizá-los, sem fazer recortes tendenciosos, sem leituras simplistas, despindo-os então de nossos preconceitos. A geografia clássica (chamada pejorativamente de "tradicional”) é supreendentemente complexa em suas hipóteses, teorizações, explanações, 
principalmente no que se refere à relação sociedade-natureza, e ao papel das influências ambientais sobre a cultura. (ideia das influências ambientais).

O objetivo deste artigo é desfazer alguns mal-entendidos na história do pensamento geográfico, enfatizando a falsa dualidade determinismo-possibilismo.

Antes de nos concentrar na explicação dessa falsa dualidade, é importante trazer um breve panorama dos conceitos contrastantes identificados por Lewthwaite, alguns dos quais são na verdade falsamente contrastantes. Lewthwaite, um dos comentadores mais tenazes e cuidadosos a tratar da ideia das influências ambientais, reconhece que o possibilismo e o determinismo são contrastantes apenas em suas versões idealizadas. Alguns conceitos contrastantes falsamente tidos como "pólos antagônicos", segundo Lewthwaite (1966):

\begin{tabular}{ll}
\hline 1. Environmental determinism & 1.Possibilism \\
\hline 2. The environmental definition of geography & 2. Other definitions, e.g., areal differentiation \\
\hline 3. Universal determinism or necessitarianism & 3. Free will or libertarianism \\
\hline 4. General, complex determinism & 4. Particular single-factor determinisms \\
\hline 5. Geographic or environmental determinism & 5. Particular nonenvironmental determinisms \\
\hline 6. General "strategic" determinism & 6. Particular "tactical" deterministic systems \\
\hline
\end{tabular}

Segundo o vocabulário técnico e crítico de filosofia Lalande, "necessitarismo" é um termo antiquado para designar "determinismo" termo esse reprovado por J. S. Mill. De acordo com Lallande, "necessidade" é a "pressão exercida sobre os desejos e as ações do homem pelo encadeamento inevitável dos princípios e das consequências, dos efeitos e das causas. Muitas vezes personificada neste sentido, e por vezes, confundida com a fatalidade." (LALLANDE, 2007, p. 728).

A partir da ideia de Lewthwaite, em esquematizar alguns conceitos contrastantes, resolvi propor uma nova esquematização, que na verdade lista apenas as falsas dualidades, cujos binômios guardam entre si semelhança ou simplesmente são conceitos totalmente distintos, que não se opõem, não se excluem e não são contraditórios. Esses conceitos falsamente contrastantes são analisados por Lewthwaite, e sobre o contraste determinismo ambiental/possibilismo, ele acredita que são, sob alguns ângulos, de fato contrastantes, mas sob outros, complementares. As falsas dualidades aparecem da seguinte maneira:

\begin{tabular}{ll}
\hline 1. Determinismo ambiental & 1. Possibilismo \\
\hline 2. Determinismo ambiental & 2. Probabilismo \\
\hline 3. Conceito ambientalista da Geografia & 3. Possibilismo \\
\hline 4. Princípio corológico & 4. Determinismo ambiental \\
\hline 5. Princípio corológico & 5. Conceito ambientalista da Geografia \\
\hline
\end{tabular}


Sobre esses conceitos falsamente contrastantes, Lewthwaite comenta que

Definition of geography as the study of man-environment relationships is by no means the same thing as environmental determinism, indeed most of those who held the former concept vigorously repudiated the latter. They are false antitheses which place the environmentalist concept of geography in opposition to possibilism, and which envisage the chorological (or areal-differentiation) principle as logical contrary to environmental determinism. (LEWTHWAITE, p. 19)

O autor Segue afirmando que o correto é entender que "The real contrasts are those which divide the environmentalist definition of geography from other definitions, and separate environmental determinism (as usually conceived) from possibilism." (ibid, p.19).

Lewthwaite mostra-se bastante preciso e perspicaz quando esclarece que o determinismo ambiental, conforme concebido erroneamente pela crítica, é considerado antagônico ao possibilismo, pois, modelos à parte, o que realmente veio a ser o determinismo ambiental - ou seja, o real determinismo, aquele que foi advogado e teorizado por seus defensores - não é de modo algum contrário ao possibilismo, que por seu turno também foi mal compreendido por seus críticos.

Quanto ao problema da relação entre determinismo ambiental e probabilismo, Tatham (1957) afirma que este último é um determinismo mascarado, invertendo a lógica de Lewthwaite (1966); Sprout (1950) e Spate (1952), para quem é o determinismo que consiste num probabilismo mal compreendido e por vezes um pouco radical, ou seja, um probabilismo "mascarado" por exageros da crítica ao determinismo e por exagero dos próprios deterministas. Assim, no momento em que surgiu o termo "probabilismo" na Geografia, com Spate, teve-se a falsa impressão de que se tratava de um "avanço", ao não radicalizar nem a influência do ambiente, nem a ação e a liberdade humana. Mas deterministas e possibilistas já agiam dessa forma ponderada, e o probabilismo então pode ser considerado como algo muito próximo do que realmente pensavam os defensores do determinismo e os do possibilismo.

Lewthwaite, apesar de não ver no conceito ambientalista de Geografia um comprometimento cego com o determinismo ambiental ou com o possibilismo, enxerga o que considera o real problema, o fato de que esse conceito era, simultaneamente, muito inclusivo e muito exclusivo. Inclusivo, por sugerir que qualquer tipo de relação homemmeio estaria na mira do geógrafo, ou, ao menos, por falhar em especificar que tipos de relações cabem ao geógrafo. 
Admitindo-se que a Geografia é o estudo da relação homem-meio, então estaríamos adentrando as áreas de pesquisa de dezenas de ciências que também têm esse foco. O geógrafo estaria incumbido de estudar temas muito distantes de sua formação e realidade, como por exemplo, a obra sinfônica de Richard Strauss "Das alpen simphonie" (Sinfonia Alpina), colosso sinfônico que representa as impressões do compositor alemão ao passar um dia de verão nos Alpes Suíços. Há menções a fenômenos climáticos, a períodos do dia, animais, plantas, ou seja, seria um prato cheio para o geógrafo estudar as influências da natureza sobre a percepção e sensibilidade do compositor. Não se quer aqui negar que isso pudesse render bons frutos, pois certamente seria assunto instigante para a Geografia cultural e da percepção, mas como pesquisa, foge bastante aos objetivos da Geografia física, por exemplo, e às habilidades dos geógrafos em geral, que raramente são especialistas e estudiosos de música erudita. O referido tema serve, antes, como exemplo da relação música-espaço geográfico (no caso, ambiente físico, especificamente), mas não se constitui num campo de trabalho necessariamente ideal para o geógrafo, considerando-se que pode haver profisisonais mais competentes, em tese, para realizar tal estudo. Inúmeras áreas do conhecimento humano estão relacionadas ao ambiente, como a pintura e a poesia, e isso não significa que o geógrafo tenha que estudar os quadros de Monet ou os poemas de Goethe pelo mero motivo de terem relação com a natureza.

Ao mesmo tempo, essa visão de Geografia pelo viés homem-meio é excludente, pois implica em ignorar uma série de temas; tanto da Geografia física, como o estudo de microclimas de cavernas, de modelagem do relevo pelas forças naturais, de aspectos meteorológicos e climáticos de furacões; quanto da Geografia humana, como o papel das relações políticas na formação do território, o estudo da violência urbana, ou das tensões étnicas nos fenômenos migratórios. Lewthwaite, em sua crítica, não mencionou os temas da Geografia humana que não tratam da relação homem-meio, citou apenas alguns exemplos da Geografia física, como o estudo de montanhas na Antártica. Ao ser excludente, a Geografia da relação homem-meio estaria ignorando as relações naturezanatureza e as interações cultura-cultura.

Lewthwaite escreveu seu artigo sobre o determinismo na década de 60, com comentários que se referem também à década anterior, e persiste em seu texto uma contínua referência às duas visões de Geografia na época: a corologia (diferenciação de áreas) e o conceito ambientalista (relação homem-meio). Sobre a corologia explica que havia muita incompreensão dos que achavam que ela implicava uma não observância do estudo da relação homem-meio ou que dissolveria a distinção homem-natureza. Os adeptos do conceito corológico apenas acreditavam que a relação homem-meio não definia a Geografia, ou seja, 
tal relação não podia restringir os escopos da Geografia. Assim, as relações ambientais eram consideradas apenas como explicação das diferenças areais. Para os que fizeram estudos corológicos, o conceito ambientalista foi pretensioso em colocar sua "carruagem ambiental" na frente do "cavalo corológico".

\section{DETERMINISTASE POSSIBILISTASSÃO GÊMEOS UNIVITELINOS NO MESMO BERÇO AMBIENTAL?}

Sobre a querela determinismo/possibilismo, esta parece ter sido uma espécie de "guerra fria” do pensamento geográfico nas primeiras décadas do século XX. As críticas trocadas parecem ter raramente tocado nas principais fraquezas de ambas as teorias, e por vezes resvalaram para deboches improdutivos e críticas superficiais. Ou seja, a guerra de fato, que seria a elaboração de críticas contundentes, extensas e detalhadas, de fato não houve. Críticas mais perspicazes, ainda que breves, emergiram na década de 50 e 60, e em menor escala nas décadas seguintes, quando alguns autores, como Lewthwaite (1966); Martin (1955); Speth (1978); Spate (1952); Peet (1985; 1993) e Montefiori (1955), escreveram artigos para defender suas posições e suscitar novas nuances na crítica ao possibilismo e ao determinismo. Glacken (1967), também muito atuante na década de 60, escreveu imensa obra na qual reserva uma longa parte para discutir a ideia das influências ambientais, mas não se refere ao determinismo, usa, em seu lugar, os termos "teoria ambiental" e "teoria climática”. É o único geógrafo que ignorou completamente o uso do termo determinismo. É também o autor da Geografia que mais e melhor escreveu sobre as teorias deterministas, enquanto que cabe a Lewthwaite o mérito de ter elaborado a maior e melhor crítica à "crítica do determinismo".

As décadas de 80 e 90 constituem períodos em que não houve nada relevante em termos de avanços epistemológicos e conceituais na compreensão do determinismo geográfico na história do pensamento geográfico. A bibliografia era escassa e se reduzia a obras ligeiras e fragmentadas de história do pensamento geográfico.

Sobre a ideia das influências ambientais, no alvorecer do século XXI são publicadas algumas obras de Jared Diamond (2007; 2009), e o debate sobre o determinismo ambiental tem sido retomado, ainda que timidamente, com algumas críticas esparsas e pouco convincentes, direcionadas a Diamond, e que pela cegueira paradigmática e preconceito, pecam pelo excesso. As décadas de 50 e 60, principalmente entre o período 1948-1957, mostraram-se as mais profícuas quanto à discussão do determinismo na Geografia, seguida por outro produtivo período entre 1965-1978. 
O determinismo ambiental não deve ser concebido como um rótulo dado a uma teoria que advoga determinação absoluta e única de fatores ambientais. Assim, é preciso esclarecer que o emprego do termo comporta todas as nuances possíveis entre um inexistente determinismo fatalista e absoluto e uma igualmente inexistente visão ingênua de que o livre arbítrio humano é total, contrapondo-se a uma natureza passiva e domável. Esses extremos representariam uma versão metafísica idealizada do determinismo e do possibilismo. Essas duas teorias, na realidade, estão longe de serem pólos totalmente antagônicos, pois seus discursos por vezes se aproximam e diferem apenas na linguagem, na retórica, na terminologia, e às vezes na ênfase dada ao peso da influência ambiental. Além disso, os discursos possibilistas parecem bastante compatíveis com outros determinismos, que não o ambiental, e dessa forma, quando reconhecemos algum grau de determinismo psicológico, econômico ou social na explicação da cultura e da sociedade, estamos colocando em cheque, tanto quanto no determinismo ambiental, a tão venerada liberdade humana que permite a escolha dentre as possibilidades oferecidas pela natureza.

O determinismo ambiental absoluto jamais existiu, senão nas esquinas das fantasias da "criticolândia". Restou do desmoronamento dessa crítica, um determinismo atenuado, chamado de probabilismo, rótulo esse menos impreciso para se referir à hipótese explanatória básica da ideia das influências ambientais. Do mesmo modo, o determinismo filosófico absoluto (chamado de "determinismo total ou geral" por Lewthwaite), também jamais existiu no discurso dos autores "deterministas", senão como modelo metafísico especulativo, enquanto que na ciência, esse determinismo absoluto tem sido gradualmente solapado desde o advento das teorias revolucionárias de Albert Einsten, Max Planck e Heisenberg. Sobre esse abandono do determinismo absoluto que tem dado lugar ao probabilismo e à noção de "condição", Abbagnano esclarece que:

Primeiro a teoria da relatividade e depois a mecânica quântica puseram em xeque a noção de causalidade necessária e, por conseguinte, a de determinismo absoluto. (... Max Planck, descobridor do quantum de ação, escrevia que, para poder salvar a hipótese do determinismo rigoroso, era necessário pensar num espírito ideal, capaz de abranger todos os processos físicos que se desenvolvem simultaneamente e, portanto, de predizer com certeza e em todos os detalhes qualquer processo físico). (... o abandono da causalidade necessária e da doutrina do determinismo absoluto, que transformara a causalidade necessária em princípio universal do conhecimento científico, parece sancionado pelas maiores autoridades científicas de nosso tempo). Todavia, esse abandono não é, automaticamente, a aceitação do indeterminismo, ou seja, do reconhecimento do acaso e do arbítrio absoluto nos fenômenos naturais. Assim como o abandono da noção de causa coincide com o uso cada vez mais amplo e consciente da noção de condição, também o abandono da noção de determinismo absoluto, paralela à primeira, coincide com a aceitação de uma forma de determinismo que se vai esclarecendo paralelamente ao esclarecimento do conceito de condição. Ao declarar inutilizável o conceito de causa, a física contemporânea insistiu na possibilidade de previsão provável; e ao declarar, por isso mesmo, a queda do determinismo absoluto, tende a adotar um determinismo restrito 
[Transposto ao universo do determinismo ambiental, "determinismo restrito" é sinônimo de "probabilismo"] ou, como diz o próprio De Broglie, "fraco" ou "imperfeito", fundado no reconhecimento de que "nem todas as possibilidades são igualmente prováveis" e de que "todo estado de um sistema microscópico comporta certas tendências que se expressam pelas diferentes probabilidades das diversas possibilidades nele contidas" (...) Portanto, a palavra "determinismo" não foi abandonada, mas sofreu uma transformação radical na linguagem científica e filosófica contemporânea. Não designa mais o ideal de causalidade necessária e de previsão infalível, mas o método de conexão condicional e de previsão provável. (ABBAGNANO, 2007, p. 289)

A confusão semântica que tem permeado a crítica ao determinismo ambiental encontra um paralelo na "oscilação semântica" que, segundo Abbagnano (2007), tem sido notada na atual filosofia da ciência e no passado:

Se a oscilação semântica do termo "determinismo"” é perceptível na filosofia da ciência contemporânea, sobretudo em relação à diferente ontologia pressuposta pela física do século XX (em particular a quântica) em relação à física newtoniana ou em relação aos diferentes níveis de aplicação - físico, social e psíquico -, não é menos verdade que o termo teve diferentes significados também no passado, a ponto de torna-se extremamente problemático e equivocado. (id)

Sobre a dualidade determinismo/possibilismo, Lucien Febvre (1925), historiador francês, em seu livro "A Terra e a Evolução Humana", foi um dos grandes colaboradores na criação e disseminação dessa falsa dualidade, que é fruto de uma redução do conflito teórico-ideológico de sua época, estabelecido entre as enclausuradas geografias nacionais da Alemanha e da França. Assim, cada uma dessas escolas ficou impregnada com os rótulos: Determinismo (imposto a Ratzel) e Possibilismo (imposto a La Blache), respectivamente. Essa estigmatização contribuiu para criar imagens errôneas sobre os dois autores, e por muito tempo Ratzel foi rotulado como um "voraz determinista geográfico” e La Blache como um "inocente possibilista geográfico". Hoje essa concepção foi superada e o recorte abstrato de Febvre foi relativizado, afinal, nenhum dos dois Geógrafos enquadrava-se completamente nas "escolas" a eles atribuídas.

Sobre a falsa dualidade determinismo/possibilismo, Lewthwaite expressa sua visão afirmando que:

It is, therefore, a Gross simplification to pit environmental determinism against possibilism (or indeed any other determinism) as discrete and imcompatible alternatives. They may be at opposite poles in the long continuum of man-environment relationships, but their positions merge and blend into complementarity. (LEWTHWAITE, 1966, p. 17) 
Para Freeman (1961), alguns fatos da experiência humana demandam aceitação da tese determinista, enquanto outros fatos simplesmente só podem ser entendidos ao se enfatizar a iniciativa humana. Referindo-se ao sistema determinista usado por Taylor (1945) e ao sistema cultural usado por Carter em seus respectivos estudos, Lewthwaite elucida que "in essence, at least, these are scarcely as contradictory as their exponents seem to have thought, and each may yet be invoked as contributing some valuable insights to the overall interpretations of man-land relationship." (LEWTHWAITE, 1966, p. 17).

A exacerbação da dualidade determinismo-possibilismo só ocorreu por rixas acadêmicas e contendas político-ideológicas, e também porque se fixou em demasia nos seus conceitosmodelo, que não passam de abstrações que fazem sentido apenas num contexto metafísico, como explica Lewthwaite ao conceituar como

Environmental determinism, pure and undiluted, provides a conceptual model with culture reduced to uniformity and human action varying only in response to environmental limitations and opportunities." Por sua vez, "Possibilism, pure and undiluted, may be conceived as a different deterministic system with the environment reduced to uniformity and human will and culture introduced as the sole variables. Of course such situations do not exist on the earth - nobody ever thought they did! [Há sim, críticos, principalmente no Brasil, que atribuíram essas ingenuidades a alguns deterministas, como Demolins, Montesquieu e Semple]. But they may be assumed for analytical purposes. (id)

Daí decorre que determinismo e possibilismo devem ser vistos mais como modelos úteis para propósitos analíticos ou como rótulos ideologicamente impostos a dois discursos enquanto meras abordagens do mesmo problema - cada qual baseado em suas próprias e apressadas premissas e devaneios - discursos esses que têm mais aspectos convergentes e semelhantes do que seus interlocutores e respectivos leitores fizeram parecer ao longo dos debates travados na primeira metade do século XX. Para Lewthwaite, os dois termos são alçados em alguns discursos de seus opositores a um elevado patamar de polêmica e de estereotipagem, fato que nos faz acreditar que estavam em jogo nas controvérsias outros interesses, como disputas acadêmicas, políticas, nacionalistas, além de partidarismos científicos e até mesmo rusgas pessoais, fator esse que não pode ser subestimado.

Em algumas obras de Febvre (1925); Brunhes (1962) e La Blache (1946), a importância dada aos fatores ambientais é tamanha que por alguns momentos já não sabemos se estamos lendo uma obra possibilista ou determinista. Febvre e Semple, tidos como uns dos principais representantes do possibilismo e do determinismo, respectivamente, chegam a expressar as mesmas ideias com palavras distintas, conforme se pode observar nas duas citações a seguir: 
"Men can never entirely rid themselves whatever they do of the hold their environment has on them" (FEBVRE, 1925, p. 315). "Civilization has lengthened his leash and padded his colar so that it does not gall; but the leash is never sliped" (SEMPLE, 1911, p. 70). A frase de Semple lembra ideia possibilista que reconhece a permanência das influências ambientais e a capacidade dos humanos em fazer escolhas e amenizar essas influências. Fevbre usa o termo "hold" para se referir ao domínio que o ambiente tem sobre o homem. A esse domínio Semple também se referiu, porém fazendo a analogia com a coleira (coleira que segura e que se torna mais larga, estofada e confortável, porém sempre presente). “To hold” significa, dentre outros sentidos, "segurar". Segurar significa dominar, ter controle sobre. O termo "coleira", usado por Semple, também se refere ao controle, domínio, ao segurar quem está por ela envolto. Assim, fica claro que ambos os autores expressaram a mesma ideia com palavras distintas.

Febvre também afirma a inevitabilidade da influência dos fatores ambientais ao dizer que "o homem, independentemente do que possa fazer, nunca pode se livrar completamente do domínio que o ambiente exerce sobre ele". Semple, ao falar do alargamento e estofamento da coleira, reconhece que um maior nível de desenvolvimento de uma civilização leva-a a uma maior independência dos fatores naturais, o que abre um amplo leque de possibilidades. Tatham, assumidamente possibilista e crítico de Taylor, afirma que além dos fatores científicos, outros como ganância, vontade, desejo e capricho alargam a tal coleira aludida por Semple.

As similaridades entre possibilistas e deterministas são tantas, que levaram o antropólogo Franz Boas, na década de 20, a impingir o rótulo de "determinista" a inúmeros autores considerados na época como "possibilistas". Segundo Speth (1978), "Boas named or implied Ritter and Ratzel, Vidal de La Blache and Brunhes, and Guyot, Semple and Huntington as carriers of the environmentalist banner". O fato de Boas não ter incluído na lista o grande expoente da Geografia evolucionista William Morris Davies permanece uma intrigante questão" (SPETH, 1978, p. 45).

$\mathrm{O}$ falso antagonismo possibilismo/determinismo que tem se arrastado por quase um século é certamente falso e pode ser diluído quando abordamos o estudo da relação homem-meio na Geografia levando em consideração três premissas lógicas e inevitáveis:

a. A natureza atua inexoravelmente dentro de circunstâncias;

b. O ser humano atua inexoravelmente dentro de circunstâncias;

c. Essas circunstâncias comportam fenômenos humanos e naturais, regidos por sistemas probabilísticos, e tais fenômenos envolvem sociedade e natureza, em perpétua interação, comportando ordem, desordem, leis e acaso, caos e complexidade, ciclicidades, entropia, incertezas. 
Assim, fenômenos humanos e fenômenos naturais acontecem inscritos num contexto de influências de diversas naturezas, do que se infere que se torna impossível isolar causa e efeito. Separar as influências ambientais das não ambientais mostrou-se inviável em muitos casos, e tais impossibilidades constituem-se num dos principais alvos da crítica à teoria ambientalista.

Sobre a dualidade determinismo/possibilismo, Moreira (2006, p. 167) afirma que "A intervenção do historiador Lucien Febvre introduziu na história do pensamento geográfico um contraponto, inexistente, entre La Blache, e Ratzel envolvendo uma dissonância das respectivas abordagens da relação homem-meio, em que La Blache seria possibilista e Ratzel determinista", e reconhece que a conseqüência disso é um obscurecimento do verdadeiro contraponto que desponta no ocaso do século XIX, "aquele estabelecido entre o olhar regional fracionário de La Blache, inspirado numa concepção isolacionista de região, um caso de singularidade, e o olhar diferencial e corológico de Hettner, inspirado na região como uma diferenciação de áreas, bem analisado por Hartshorne (1978).” (MOREIRA, 2006, p. 167).

O possibilismo não é uma teoria, e sim, um discurso que tampouco pode ser oposto e concorrente ao determinismo, visto que dele quase não difere, ou difere apenas quanto à intensidade do foco ou ênfase, uma vez que comporta a pergunta: até que ponto o homem pode atuar sobre a natureza para seu próprio benefício e para amenizar ou suprimir suas influências? Ou seja, a ênfase não seria o grau de influência do ambiente, mas sim o grau de influência humana sobre o ambiente.

A única resposta segura a esse questionamento é a de que ao homem sempre cabe atuar/reagir diante das influências do ambiente ou sobre elas, nem que essa atuação ocorra apenas na forma de adaptação a determinados efeitos da natureza. Ao construir casas com telhados inclinados para evitar seu desabamento pela neve acumulada, o gênio humano estaria anulando essa faceta da força climática (capacidade de causar desabamento) por meio de uma estratégia de adaptação. Ou seja, na impossibilidade de impedir a ocorrência de fortes nevascas (apenas nesse sentido é possível afirmar que a natureza é imperativa e impõe aos humanos a necessidade de adotar certas estratégias, pois as nevascas vão acontecer queiramos ou não), adota-se uma série de estratégias em relação aos transportes, à arquitetura e à agricultura, anulando ou amenizando outros efeitos da nevasca enquanto força climática que obriga o homem a adaptar-se ou a ir embora do local que se encontra sob a ação dessa força. Advogar um determinismo absoluto e radical seria estabelecer uma lei geral que afirma que em todas as regiões de intensas nevadas a ocupação humana é e será sempre impossível. Ninguém nunca advogou esse exagero, o que mais uma vez mostra que o tal determinismo radical e absoluto jamais existiu na história das ideias. 
Mesmo quando se afirma que certo tipo de relevo ou vegetação dificulta o povoamento de uma área, ainda assim existe margem para a ação humana, uma vez que "dificultar" difere enormemente de "impedir". Por exemplo, uma determinação implacável, com verdadeiro impedimento, pode ser atribuída às longas distâncias oceânicas entre os povos dos primórdios da humanidade. Os oceanos não "dificultavam" o intercâmbio e a disseminação dos povos que desconheciam a navegação, mas impediam-no totalmente ao menos durante certo período, já que em climas passados havia supostamente uma ligação entre Ásia e América no estreito de Bering congelado, e em séculos recentes a navegação superou, em grande parte, o obstáculo das distâncias oceânicas.

No possibilismo, por seu turno, ao reconhecer que a ação humana tem limites, ele comporta, ainda que nem todos os seus interlocutores reconheçam isso, uma grande consciência das forças ambientais influenciando a sociedade em diversos aspectos e gerando obstáculos. Assim, poderíamos conjecturar que ambas as ideias, determinista e possibilista, comportam uma expressiva preocupação com as influências ambientais, mas que certos interlocutores de cada lado pecaram, por vezes, ao exagerar em seus argumentos e ao utilizar exemplos indevidos e polêmicos.

Lewthwaite explica que nenhuma das duas “teorias" (que devem ser vistas de fato como sistemas determinísticos) pode ser ignorada, e argumenta lucidamente sobre a importância dessas abstrações da seguinte forma:

Thus environmental determinism and possibilism may both be viewed as valid if given their proper place within a necessarily broader framework and used with discernment and discretion as constructs which cover some but not all of the facts. [Os autores "deterministas" jamais propuseram suas teorias como capazes de explicar e prever "all of the facts", e esta é uma das falhas da crítica, que lhes atribuíram essa ousadia.] Viewed from this angle, determinism and possibilism represent the opposite poles of a total spectrum which includes every possible position. As the Sprout concluded 'random guessing in neither a fruitful nor a necessary alternative to determism. Between the extremes of predictable certainty and total unpredictability... lie the concepts of possibility and probability, the latter in many gradations of uncertainty...these concepts, and the man-milieu relationship hypothesis into which they are incorporated, constitute useful and widely used general premises for calculating within some range of uncertainty the boundaries and patterns of things to come. Sometimes it is the deterministic pole which will be approached and at other times it is possibilism which will be approximated, but to oppose these as mutually contradictory positions is not only unrealistic but obscures the element of value in each. It is better to view them as abstractions, conserve the truths idealized in each system, and apply these principles to the real situations which are bound to vary with culture, time, and place. There is no need to assume that any one of these constructs or even all of them together will cover all of the facts and exclude the random play of contingent factors. But each may perhaps qualify as a deterministic system covering enough of the facts to be a useful analytical tool permitting a measure of extrapolation, retrodiction, and prediction. [A explanação ou interpretação de eventos ou ações passadas, inferida a partir de leis que se assumem governá-las. Os autores deterministas se preocuparam muito mais com retrodição do que com previsão.]. (LEWTHWAITE, 1966, p. 19) 
Para demonstrar a cegueira de alguns críticos em relação à similaridade entre determinismo ambiental e possibilismo (ambos diluindo convergentemente ao probabilismo), gostaríamos de citar alguns exemplos de Lewthwaite, que ironicamente mostra o erro da crítica, ao contar que:

Over and over again, geographers have sought to refute determinism by elaborating on the fact that America would have been a different country if settled by Chinese, or that the aboriginal hunters of Australia used their continent in very different fashion than did the Europeans settlers. Of course! But this obvious fact need infer nothing more than the intersection of one system with another. [o que o ingênuo crítico possibilista pensa ser um forte argumento em favor do "absurdo do determinismo", não passa de evidência que mostra exatamente que não contraditam, pois a verdade que apresentam é óbvia e reconhecida por todos. Ou seja, essa crítica não diz nada, não aponta para as falhas reais dos deterministas, e sim, parte do pressuposto ilusório de que deterministas ignoram essas influências da cultura]. No more would the concentric-zone theory of urban land use be refuted if a predicted urban pattern were obliterated by an atomic bomb! [Ou seja, o acaso não impede um modelo ou um padrão de existir e poder ser previsto como provável! O padrão vai se repetir onde quer que haja as condições necessárias, logicamente assumindo-se que nenhuma obra do acaso o impeça. No caso citado, a bomba, ao destruir uma cidade, não está destruindo a validade do modelo enquanto previsão do padrão predominante para as cidades e não o invalida.]. (id)

Lewthwaite finaliza sua discussão sobre a dualidade determinismo/possibilismo resumindo suas ideias da seguinte forma: "The scientific laws are of varied character, deterministic systems and freedom may be simultaneously operative at different levels, and lawfulness and caprice are not to be posed as mutually contradictory and exclusive. (ibid, p. 19). Fecha sua ideia com importante conclusão, pois

It may be suggested, then, that solutions already indicated by the environmentalist-possibilist controversy are equally applicable to the issue of quantification and the humanistic tradition. Again, each may be viwed as occupying the extreme pole of a continuum which includes every gradation between regularity and randomness, and each and every one of these positions may be invoked whenever appropriate. (id)

Gaille e Willmont (2003) também fazem uma observação que reforça nossa preocupação com as críticas levianas e animosidades impertinentes entre diferentes "escolas" ou "paradigmas", ou, sem usar rótulos, entre distintas abordagens. Ele não menciona o determinismo por estar se referindo às três revoluções do "corpo intelectual" da Geografia na segunda metade do século XX, ou seja, posteriormente ao "trem fantasma" dos deterministas do início do século. 
These three intellectual revolutions bear some striking similarities. All were reactions to weakness in the mainstream practice of geography at the time, and all acquired converts from the pool of successful mainstream practitioner, a number of whom became the champions of the revolution. All also spawned active cadres of "true believers" who, at times, denigrated the work of other geographers as irrelevant, wrong, or counter-productive. The three revolutions and challenges to orthodoxy have all waned, but each has made an indelible imprint on American geography. (id)

Os autores reconhecem, em seguida, que apesar dos dolorosos turbilhões paradigmáticos forjados pelas três revoluções da Geografia, o saldo final na Geografia a tornou muito mais robusta. Eles reconhecem que a verificabilidade empírica promovida e expandida pelos quantitativistas, ainda que não explique todas as questões-chaves, geralmente foi capaz de aumentar e fortalecer nosso conhecimento de vários assuntos; que a abordagem dialética da revolução marxista, assim como o questionamento do sistema no qual operamos, apesar de nem sempre prover soluções práticas, pode satisfatoriamente jogar luzes sobre a relação fundamental entre economia e poder; a revolução pós-moderna, por sua vez, ainda que tenha deixado os geógrafos sem uma forma adequada para seguir em frente, ensinou-lhes a decifrar os profundos e ocultos significados dos textos geográficos, examinar os problemas da disciplina e inquirir sobre o próprio modo com que eles têm produzido conhecimento. O autor conclui seu panorama geral da Geografia dos EUA afirmando que "If there is one thing that we have learned, it is to be tolerant of alternative or even revolutionary thought as, in the end, it may be good for us." (ibid, p. 3).

Em certo ponto, a análise desses autores vale para a Geografia brasileira, pois, dada as devidas diferenças, boa parte das tendências dos EUA também se verificaram na Europa, cuja influência faz com que essa Geografia dos EUA chegue ao Brasil.

Sobre nossa mania de falar em "escolas" e "correntes de pensamento", essas reações de uma corrente em relação à outra trazem sempre um fator positivo, mas algumas, pela sua natureza equivocada, geram efeitos colaterais graves em geógrafos que encaminham essas "misconceptions" a uma enorme platéia de futuros geógrafos. Não basta selecionar bons textos para rechear uma ementa de disciplina bem intencionada: é preciso construir uma matriz intelectual, uma estrutura de pensamento na platéia, e fazer emergir um conflito verdadeiro e produtivo, resultando então num novo patamar cognitivo, permitindo aos estudantes a possibilidade de aprimorar as lentes existentes, ou substituí-las por outras, sendo essencial que entrem em contato com a lista mais abrangente possível de possibilidades e impossibilidades do conhecimento em Geografia, em especial com as limitações e possibilidades da pesquisa em história do pensamento geográfico. 
Para nos prepararmos com os devidos cuidados para a pesquisa na história das ideias, é importante não subestimarmos os autores clássicos e as fontes primárias de pesquisa histórica, de preferência dominando o idioma em que foram escritas as principais obras de nossa bibliografia, investindo no estudo em torno da teoria do discurso, e também com questões relacionadas à retórica, erística ou qualquer outra área do estudo das ideias e dos discursos, lamentando-se quanto a essas áreas o fato de que nunca fizeram parte dos currículos de Geografia no Brasil. O estudo das ideias e dos discursos têm experimentado maior disseminação na Geografia dos EUA e principalmente da França, onde vários autores como Derrida, Deleuze e Focault demonstraram profundo interesse na crítica das categorias binárias, levando seus estudiosos a uma preocupação com a reavaliação dos termos subestimados desses binários, como corpo/máquina, cultura/natureza/, masculino/ feminino, humano/animal, etc.

Sobre as revoluções na Geografia anteriormente citadas por Gaille e Willmont, trata-se das revoluções quantitativa, marxista e pós-moderna. A palavra revolução deve ser tomada como uma metáfora, ou seria muito exagero usar tal termo. Atualmente convivem, não sem tensões, todas essas geografias, incluindo-se as geografias anteriores às três revoluções.

Partindo-se da constatação da inexistência da dualidade determinismo/possibilismo apresentada neste artigo, e sendo ambos os discursos basicamente os mesmos, com apenas uma diferença na ênfase dada à influência ambiental e na retórica usada no discurso, seria possível jogar com a questão e trazer para análise alguns matizes deterministas das obras possibilistas e alguns matizes possibilistas das obras deterministas. Esses matizes mostram-se por meio dos termos empregados, das relações sugeridas e da explicitação dos fatores ambientais que influenciam o ser humano e a sociedade. Dessa forma, com o intuito de demonstrar que podemos imprimir a uma obra o tom que bem queremos dela, selecionamos alguns trechos de obras reconhecidas pela crítica como "deterministas" e alguns trechos de obras "possibilistas", de tal forma que trechos de obras possibilistas parecem traduzir o pensamento de um autor tipicamente determinista ao passo que trechos de obras deterministas podem soar tão brandas a ponto de parecerem um bordão clássico de obras possibilistas, ou seja, o circo da crítica equivocada pega fogo, pois seus rótulos simplesmente não resistem a um simples escrutínio baseado na leitura imparcial das rotuladas obras.

Os sêres humanos, em si mesmos e por si mesmos, são fenômenos de superfície e, portanto, fatos geográficos. Vivem sôbre a terra. Estão submetidos às condições atmosféricas e terrestres. Pertencem a certos climas, a certas altitudes, a certas zonas. Além disso, êles vivem na terra: subordinando-se aos fatos naturais é que assegurarão a seus corpos o cuidado indispensável e a suas faculdades o desenvolvimento e o florescimento. (BRUNHES, 1962 p. 26) 
É bastante intrigante que na história do pensamento Geográfico não se tenha rotulado Brunhes de "determinista", com base nesse recorte: "Os sêres humanos estão submetidos às condições atmosféricas e terrestres.", é bastante clara ao indicar o papel passivo do homem e o papel dominante das forças naturais, e tais papeis foram lembrados por todos os grandes geógrafos de sua época, tal consideração não era contestada, pois os fatos da realidade a confirmam cotidianamente. Essa citação isoladamente confere um ar "determinista" a Brunhes, mas entendida no todo da obra, ao se conhecer outras obras e ao se dominar o pensamento de Brunhes, o leitor poderá fazer uma avaliação livre de rótulos, seja ele "determinista" ou "possibilista”. Em outro trecho, Brunhes afirma que

(...), determinadas condições geográficas fundamentais (situação topográfica, altitude, orientação, proximidade do mar, dimensões do espaço conquistado ou ocupado, etc.) desempenham tal papel nos destinos das cidades, das províncias ou dos países, que a história dêsses fatos não pode estar livre de tôda consideração geográfica. Mais do que isso: a história humana mergulha, por tôdas as suas raízes, (...) na sua realidade material terrestre. (BRUNHES, 1962, p. 52)

Nesse recorte, Brunhes enfatiza a potente força dos fatores ambientais na história da humanidade. Para ele, o historiador prudente não pode jamais ignorar ou subestimar a força das influências ambientais/geográficas no curso da história, na explicação dos fatos históricos. Essas ideias são as mesmas expressas por Semple, Huntington, Ratzel, autores que, ao contrário de Brunhes, foram taxados e "incriminados" como "deterministas". O chamado "determinismo geográfico" foi o principal bode expiatório da Geografia nos séculos XIX e primeira metade do século XX, e chegou até mesmo a ser considerado o culpado pelo descrédito da Geografia enquanto ciência.

Com o intuito de comparar o "possibilista" Brunhes e a "determinista" Semples, segue um recorte desta última, infelizmente desconhecido da crítica: “(...) dessa forma, propositadamente evitei definições, fórmulas e a enunciação de regras rápidas e rasteiras. (...) Por essa razão falo de fatores e influências, evito o termo determinante geográfico e refiro-me com extrema cautela ao controle geográfico." (SEMPLE, 1911, p. vii).

A citação acima foi extraída da obra "Influences of geographical environment on the basis of Ratzel's system of anthropo-geography”. Segundo Jardim de Carvalho Jr (2012b), tal obra constitui-se numas das mais polêmicas de toda geografia, ao lado de "Civilization and Climate", de Huntington, e sua importância climatológica, epistemológica e teórica tem sido subestimada. A leitura da obra mostrou tratar-se de um grande clássico da Geografia, escrito sob uma ampla veia poética e plena de metáforas que não podem ser lidas literalmente. $\mathrm{O}$ pensamento de Semple se mostrou muito complexo, até mesmo para os padrões atuais de pesquisa, e sua importância científica e educacional deve ser reconhecida pela comunidade resclis 
acadêmica, principalmente no que concerne a instigante relação sociedade-natureza e o papel das influências ambientais sobre a sociedade.

A citação acima referida, justamente porque contraria o estereótipo determinista, nunca foi citada pelos críticos de Semple, que fazem recortes tendenciosos, apresentando aos seus leitores uma interpretação limitada e baseada em rótulos, pois tais críticos apresentam apenas uma ou duas citações mais poéticas e metafóricas, como "prova" do "crime determinista" da autora. Ora, não se pode julgar, e isso é um cânone acadêmico dos mais sagrados, um autor da complexidade de Ellen Semple, ou Ratzel, ou Huntington, apenas com base em umas poucas frases, selecionadas justamente por serem ou as mais descuidadas de seus autores, ou aquelas metafóricas, poéticas, densas, ou dúbias e que, portanto, podem render incompreensões. A referida citação revela uma ideia típica de cautelosos autores "possibilistas", cientes de que é preciso muita precaução ao falar de influências geográficas, e que o termo "determinar" é perigoso e impróprio. Inclusive, essa citação, isoladamente, revela antes um autor possibilista, ao passo que as citações anteriores de Brunhes parecem apontar para um autor mais "determinista".

Outra comparação muito interessante é aquela que pode ser feita, por meio de citações, entre o "possibilista” la Blache e o "determinista” Huntington. Segundo La Blache,

As sociedades humanas, assim como o mundo vegetal e animal, são compostas de diferentes elementos sujeitos às influências do ambiente natural. Sobre as pessoas, apesar de tudo que podem fazer, condições circundantes deixam sua marca, e na Austrália, na província do Cabo ou na América, essas pessoas estão lentamente ficando saturadas com a influência das regiões onde seus destinos serão revelados. (LA BLACHE apud TATHAM, 1951, p. 156)

La Blache é considerado, pelo pensamento geográfico vigente, o grande "pai” do "possibilismo geográfico", e qual não foi nossa surpresa ao nos deparar com citações como a anterior, e a que se segue. É intrigante ler no tal "pai do possibilismo" (leitura equivocada e simplista de La Blache), a ideia de que, faça o que quiser o homem, a natureza ainda é soberana, e deixará suas marcas. La Blache fala em "sujeição", palavra que deixaria os críticos do determinismo com forte comichão. Mas nenhum crítico usou essas citações fortes para rotular La Blache de "determinista". Contudo, o antropólogo Franz Boas parece ter sido o único a autor a enxergar La Blache como um autor mais "determinista", em suas palavras "a carrier of environmentalist banner", ou seja, um autor que defendia a bandeira "ambientalista". É preciso ressaltar que na época tal termo era entendido como sinônimo de "determinista", em geral um "determinista" mais moderado, que defendia a primazia das influências ambientais sobre a história e a cultura. Para la Blache, 
A analogia dos climas fornece o fio condutor. Favorece a infiltração, dirige a força do hábito. (...) Acima de todos estes fenômenos, vivendo e agindo à nossa vista nas diversas partes da terra, paira a influência soberana dos meios. Vemo-la, exercer-se, a pouco e pouco, em quadros naturalmente apropriados. (...) A rudeza das exigências cotidianas da vida, deixando apenas subsistir os melhor adaptados, tendia a eliminar as diferenças no interior dos grupos. (LA BLACHE, 1946, p. 161-162)

Essa citação indicaria um possível "Darwinismo social” no pensamento La Blachiano ou é mero recorte que isoladamente nada significa? Esta afirmação de La Blache o coloca lado a lado com Ellen Semple, quando comparada com algumas afirmações isoladas dessa autora. Ainda não vimos sequer um comentador afirmar que La Blache é "partidário" do evolucionismo ou da analogia orgânica. Contudo, sua obra, assim como a dos deterministas, é filha de sua época, e sofreu influências do darwinismo e da onda "determinista/ambientalista" que enfatizava as forças dos fatores geográficos na marcha das civilizações, na formação da cultura, no corpo humano e na psique humana, dentre outros.

Por sua vez, Huntington explica que

Contudo, hereditariedade é apenas um dos fatores no desenvolvimento das civilizações. Religião, educação, governo, e todas as diversas ocupações humanas, costumes e instituições - sua cultura herdada como dizem os antropólogos -, formam uma segunda grande parte de influências sociais cujo poder parece quase imensurável. (HUNTINGTON, 1939, p. 1)

Com essa citação, Huntington derruba todos os seus críticos em um só lance. Apesar de enfatizar o clima como uma força primordial na explicação das civilizações, na polêmica obra "Civilization and Climate", Huntington tinha uma formação ampla, e valorizava os fatores humanos, como religião, instituições e hábitos, considerando-os dotados de um poder quase imensurável sobre o homem e a sociedade, ou seja, para ele, fatores geográficos como solo, posição geográfica e clima, não são meros imperadores a subjugar a espécie humana, mas interagem e agem por intermédio da cultura e de todos os fatores humanos em questão.

Segundo Jardim de Carvalho Jr (2012a), Huntington foi condecorado com o rótulo “determinista”, estreando-o, após a publicação de “The pulse of Asia”, em 1907 , obra que apresentou um ponto de vista que rapidamente provocou reações em todo país. Martin observa que os críticos não leram o prefácio (como de praxe, também não leram o de Ellen Semple), no qual Huntington alertava que "O leitor deve examinar cuidadosamente estas páginas tendo em mente que ele está presenciando uma teoria em processo de construção" (ibid, p. xv), ou seja, Huntington avisa que está publicando uma teoria inacabada, e isso jamais foi anticientífico. Martin explica que os primeiros escritos de Huntington claramente denotam uma postura "ambientalista", pois havia uma busca continua dos efeitos do ambiente 
sobre o indivíduo e sobre a sociedade humana. Note-se que o termo usado foi "ambientalista", termo que, às vezes, é usado não como sinônimo de "determinista ambiental radical", mas sim, de "determinista ambiental moderado", ou seja, praticamente um "possibilista". Uma análise cuidadosa da obra de Huntington parece revelar que seu pensamento possibilista é tão ou mais marcante que o de La Blache, constatação que parece chocante considerandose os equívocos de muitas obras de história do pensamento geográfico que foram hábeis em rotular levianamente.

Quanto à questão do livre-arbítrio, os escritos de Huntington mostram claramente que ele não negava ao homem a capacidade de fazer escolhas, e apontam na mesma direção do possibilismo e do probabilismo que duas décadas mais tarde seria sugerido por Spate (1952):

\begin{abstract}
No prefácio de "O Habitat Humano" (1927), Huntington escreveu: "O ambiente físico nunca impele o homem a fazer qualquer coisa, a compulsão reside em sua própria natureza. Mas o ambiente de fato diz que algumas condutas são permissíveis e que outras são impossíveis". Ao revisar a obra "Caráter nacional e os fatores na sua formação", de Ernest Barker (1927), Huntington revelou mais uma vez sua simpatia com o ponto de vista 'possibilista': "Os geógrafos estão finalmente vindo a reconhecer a tese central de Dr. Barker, que discute o ambiente físico." 'O ambiente não diz ao homem que ele deve fazer isso ou aquilo. Ele meramente diz 'aqui estão as possibilidades. Escolha qual você deseja. Ou escolha uma agora, e outra mais tarde.' Ele poderia talvez fazer muito bem em ir de alguma forma mais adiante, ao apontar que o ambiente limita as possibilidades de forma a mostrar ao homem que apenas algumas poucas possibilidades provarão serem lucrativas num certo estágio do progresso humano... Mais uma vez, ele volta-se para a ideia de que "a escolha do homem determina seu ambiente mais do que o ambiente determina sua escolha. (SPATE, 1952, p. 241)
\end{abstract}

De acordo com Lewthwaite (1966, p. 6), "It was Vidal de la Blache who stated that his aim was "to bring into relief the geographical factor" and Brunhes who urged that geographical studies must be dominated by the theme of relationship, but these were the very founding fathers of possibilism.”. Ou seja, esses autores possibilistas comungam da mesma ideia central do determinismo, que é enfatizar primordialmente os fatores geográficos/ambientais na explicação da humanidade, da cultura e da história, sendo a Geografia, dessa forma, o estudo da relação sociedade/natureza, homem/meio.

Sobre a eterna controvérsia determinismo \& liberdade, em todas as obras dos grandes filósofos há alguma apreciação sobre ela. Para o fazer geográfico essa questão é dispensável, apesar de ser digna de estudo em outras áreas. Na prática, essa distinção não entra no cômputo, e para a Geografia não importa provar e entender a existência ou não de liberdade em face das restrições ambientais. Entre os geógrafos menos contaminados por rótulos e slogans já há razoável entendimento de que as influências ambientais são inevitáveis, que afetam todas as sociedades independentemente de seu nível de desenvolvimento, que 
suscitam em cada sociedade diferentes reações, oferecendo uma variedade de caminhos, alguns dos quais mais prováveis, caminhos estes cuja quantidade e qualidade dependem da base natural de que dispõe a sociedade e de vários outros fatores não naturais, como cultura, economia, política, etc.

Fosse este artigo um tratado filosófico, seria possível estender a mencionada querela metafísica (determinismo \& liberdade) por meio de um estudo que se centrasse em torno da seguinte hipótese: "Em última instância, ninguém jamais agiu livremente, pois entre o desejo de agir e a ação consumada, sempre haverá a interposição de um caótico sistema de condicionantes, cuja natureza pode ser cultural, ambiental, social, psicológica ou indiscernível." Se há livre-arbítrio na ação humana, este parece indiscernível e enredado em uma teia infinita de condicionantes, que não podem ser isolados para efeito de análise e comprovação. Por essa razão, o instigante e relevante terreno de estudo, sobre até que ponto as influências ambientais direcionam os rumos das sociedades, costuma patinar no lamaçal da especulação e da probabilidade. Não é por essa dificuldade que deve ser abandonado enquanto área científica e enquanto tema geográfico, pois há várias ciências que sofrem com a imprecisão, a especulação e se fundam mais em probabilidades do que em certezas, e isso é válido para todas as ciências humanas e não poupa sequer as ciências naturais e exatas.

Um olhar na direção das especulações em torno dessa controvérsia revela que o temor dos críticos do determinismo ambiental, de que esta teoria pudesse solapar e por em cheque a volição, o livre arbítrio, é totalmente ingênuo e irracional. O filósofo disposto a argumentar contra a liberdade humana poderia levantar um número tão avassalador de condicionantes a interferir em nossas escolhas, que os tão propalados fatores geográficos ou influências ambientais, seriam apenas mais um ingrediente a compor a "matriz determinante". Ou seja, reconhecer apenas um isolado fator ambiental como responsável único pela nossa falta de escolhas e pela ação condicionada do cotidiano, ao mesmo tempo em que é logicamente insustentável (e por essa razão não foi advogado por ninguém), não pode ser encarado como ameaça ao livre-arbítrio, nem como prova e insinuação de que não cabe ao ser humano fazer suas escolhas.

Um determinismo ambiental absoluto e radical jamais existiu senão em conjecturações filosóficas e nunca foi advogado por ninguém no terreno da realidade e da empiria. Do que se infere que parte das controvérsias determinismo/possibilismo e determinação/livre-arbítrio não se sustenta senão num patamar metafísico (LEWTHWAITE, 1966; MARTIN, 1951; SPROUT, 1965). Como as controvérsias tiveram em geral um caráter bastante desvinculado das discussões em nível metafísico, nota-se que uma parte delas estava fundamentada em 
um devaneio que alimentava a ideia de que deterministas ambientais negavam a liberdade humana. Tal fantasia ainda atribuía aos deterministas a capacidade de considerar o ser humano o elemento passivo de uma relação com um ambiente ativo e imperioso.

Dessa forma, procede indagar se algum autor acusado de ser determinista de fato advogou que o ambiente natural era tão determinante a ponto de moldar o curso da história e constituir-se no único e grande determinante das ações humanas. Segundo alguns comentadores, até mesmo os deterministas bradados como radicais (Montesquieu, Buckle, Cousin e Demolins) se mostraram em suas obras um tanto maleáveis ao abrir algum espaço para a liberdade humana e para a influência de fatores não-ambientais. Os autores deterministas que mais parecem se aproximar de um determinismo cru e radical seriam, talvez com alguma ressalva, Demolins (sociólogo), Le Play (sociólogo) e Victor Cousin (filósofo), dos quais nenhum pode ser considerado geógrafo embora estudassem ocasionalmente alguns temas relacionados à Geografia. Digno de nota é o fato de que escreveram suas obras antes de 1882, data da publicação da Antropogeografia de Ratzel. Assim, esses deterministas mais radicais não podem ser considerados discípulos de Ratzel e seguidores de suas supostas ideias deterministas.

Considerando que nenhum desses "deterministas radicais" é geógrafo, o determinismo "geográfico" não deveria ser associado mais prontamente com a teoria política, história, filosofia e sociologia, respectivamente as áreas desses autores anteriormente citados? Mais uma vez, o uso do termo "geográfico" e "ambiental" é o problema em questão. Em todas essas áreas do conhecimento se fala do papel exercido pelo "determinismo" geográfico na sua história, mas seus comentadores, por criticarem esse "passado sujo" se referindo ao termo "determinismo geográfico", veiculam para a comunidade, científica e leiga, uma falsa impressão de que a origem do determinismo é na Geografia, e que é essa ciência que deve responder por sua disseminação. O termo ambiental também evoca a Geografia, basta lembrar-se da origem da disciplina na Alemanha e na França, fortemente marcada pela presença de estudos da natureza.

Pode parecer contraditório, mas o determinismo ambiental, por comportar dois significados bem distintos, pode ser avaliado da seguinte forma: 1. Ou o determinismo ambiental enquanto hipótese básica sempre existiu, desde que concebido como uma visão sobre a relação homem-meio com foco nas influências ambientais sem atribuir a elas nenhum controle exclusivo e fatalista. 2. Ou ele nunca existiu, considerando sua versão dogmática e rígida enquanto abstração no plano metafísico e considerando que sua precária existência na "criticosfera" não passou de um rótulo, de um discurso, de uma cisão ideológica e de um joguete intelectual nos embates acadêmicos dos últimos dois séculos. 
Hartshorne (1978) explica que a teoria do determinismo ambiental pressupõe uma irreal e abstrata dicotomia natural/humano, e argumenta em sua principal obra "Perspectives on the nature of geography", que essa distinção só pode ser sustentada com base na prática corrente. Todavia, a Geografia e demais ciências continuam a se referir, em seus estudos, às distinções humano/natural, sociedade/natureza, homem/meio, ser humano/ambiente, natural/cultural. Essas distinções têm sido empregadas ao longo da história da moderna ciência e continua a ser largamente utilizada por geógrafos, tanto pela necessidade teórica de simplificação e sistematização da realidade complexa e indivisível, quanto pela necessidade prática de pesquisa. O uso de tal dicotomia não deve causar nenhuma surpresa, diante da impossibilidade de se negar, na prática e no fazer científico, tal distinção, conforme aponta Martin (1951). Este autor afirma ainda que

The man-environment distinction seems in practice to be inherent and unavoidable in parts, at any rate, of the geography of man. To bar the distinction would be to rule out a considerable and fascinating field of human geography, for one can scarcely examine the whole 'man plus environment' without some analysis into 'man' and 'environment', this analysis being necessary as a method of procedure, without any reference to its validity as a real difference. The manenvironment distinction is, it seems, inescapable in human geography, and to advocate its rejection is to advocate the impossible. (MARTIN, 1951)

Dessas colocações conclui-se que é infundada a crítica ao determinismo ambiental enquanto baseado numa abstrata dicotomia. Fosse o abstrato e a imprecisão motivos para se invalidar uma teoria ou ciência, e todo o campo das ciências humanas e da filosofia deveria ser colocado à parte do mundo "verdadeiramente" científico, de preferência num baú de incertezas e imprecisões reservado às "pretensas ciências". Apesar das inúmeras críticas ao determinismo, em geral superficiais e breves, Hartshorne muito lucidamente ressalta um dos méritos dos autores deterministas ao defender que:

\begin{abstract}
Um estudo das relações do homem com o meio natural será manifestamente incompleto se não procurar responder à pergunta que indaga em que grau as atividades do homem são determinadas pelas condições desse meio natural. Deverá ser reconhecido que Ratzel e Semple e aqueles de seus discípulos acusados de estremada defesa do "determinismo" tiveram o mérito de haver procurado alcançar uma meta científica. Podemos escapar à censura de defender teorias indemonstráveis, mas dificilmente será lícito reivindicar o caráter científico dos nossos trabalhos se nos contentarmos com uma afirmação de propósitos tão vagamente expressa, que nos oriente para o estudo de relações entre a natureza e o homem sem a obrigação de procurarmos medir essas relações. (HARTSHORNE, 1978, p. 60)
\end{abstract}

Assim, parece concordar com Wooldridge and East (1951), que chamam de "cômoda fórmula" a ideia, tanto verdadeira como inútil e pouco profunda, de que são mútuas as relações do homem e da terra. 
Tatham defende o "possibilismo" do ponto de vista ecológico-ambiental afirmando que “The ideal of science must be harmony not force', writes Schrader, and in human geography the possibilist would suggest the maxim should be not conquest of, nor submission to, but co-operation with nature." (TATHAM, 1951, p. 162).

Heffernan (1999), em artigo sobre as diferentes concepções de progresso humano entre os iluministas franceses, enfoca três autores (Voley, Saint-Simon e Turgot) que ele considera precursores do "possibilismo", pela ênfase na ação humana e seu poder de controlar a natureza. Em suas palavras

It must immediately be acknowledged that these three names, though widely discussed by historians of ideas, are rarely accorded much space in the major histories of geography. This may be because all three writers belong to a strand of eighteenth-century thinking which was strongly opposed to environmental explanations of the human condition and particularly towards any form of deterministic reasoning. (HEFFERNAN, 1999, p. 126)

O termo "environmental explanation" é usado de maneira confusa pela literatura. Em princípio significa não mais que uma explanação que faz uso de argumentos em favor da importância de fatores ambientais enquanto influência sobre aspectos humanos. Contudo, por vezes aparece como sinônimo de determinismo ambiental, como nessa última citação, e assim mais uma orelha de porco é jogada na indigesta feijoada semântica da crítica ao determinismo ambiental. Em outra passagem, Heffernan revela desconhecer a teoria do determinismo ambiental e faz uma comparação entre os três autores estudados com o rótulo do determinismo: "Rather than interpret human societies as trapped by their physical environments, [Os autores deterministas não usam o termo "trap", (armadilha, ficar preso) e não afirmam que a sociedade está presa a uma armadilha do seu ambiente físico.] these three commentators emphasized the dynamism of the human mind and its power to overcome, and ultimately to control, the forces of nature." (ibid, p. 127) Esse "dinamismo da mente humana" e seu poder de superar e controlar as forças da natureza são atributos humanos jamais negados por qualquer pensador. Ao insistir a crítica no uso desses falsos contrastes entre determinismo e possibilismo, fica cada vez mais sedimentada nas mentes dos leitores uma dualidade que pouco se sustenta quando devidamente estudada.

A ênfase na liberdade humana e nas possibilidades de alterar a natureza em seu favor conferida por Voley, Saint-Simon e Turgot, no final do século XVIII indica que o possibilismo que viria 100 anos mais tarde não constitui uma novidade, ou seja, é uma teoria que apenas ganhou um nome nas mãos de geógrafos como La Blache e Brunhes. Seu conteúdo já havia sido plenamente formulado durante o iluminismo, e posteriormente foi discutido por inúmeros antropólogos, como Franz Boas. Ao falar sobre Volney, Heffernan 
explica que "The relationship between human society and the physical environment is a central theme. Volney insisted on the enormous complexity of this interaction, a view which clearly foreshadows the 'possibilism' of French regional geography under Paul Vidal de la blache a century later." (ibid, p. 138).

Condorcet, pensador iluminista citado por Glacken, é um ótimo exemplo de como certos exageros possibilistas já existiam nas teorias de iluministas, muito antes do suposto surgimento do possibilismo: "Nature has set no term to the perfection of human faculties... the perfectibility of man is truly infinite; and the progress of this perfectibility, from now on independent of any power that might wish to halt it, has no other limit than the duration of the globe upon which nature has cast us." Essa afirmação que tão ingenuamente confere aos homens um poder quase divino, ignorando, aparentemente, o papel obstaculizador da natureza (incluindo a genética), deve ser considerada mais como uma licença poética ou empolgação do momento, do que de fato uma crença sincera do seu propositor. Afirmar que o fim do planeta seria o único limite para a melhoria indefinida das faculdades humanas é algo bastante questionável. Ademais, reflete um otimismo típico do iluminismo antropocêntrico.

Sobre Condorcet e Turgot, Heffernan bem pondera que "The fact that neither could offer a convincing nonenvironmental explanation as to why some peoples had advanced further and more quickly than others from a common starting point was a serious flaw in their argument." (ibid, p. 134). O que nos garante que dois povos desenvolveram-se a partir de uma mesma base? O que significa falar em "mesmo ponto de partida"? O ponto de partida de cada povo não seria sempre minimamente distinto dos demais? De qualquer modo, os deterministas sabiam que povos diferentes lidavam diferentemente com o mesmo tipo de ambiente.

De fato, Heffernan tocou no ponto mais fraco das teorias possibilistas, pois ao enfatizarem os grandes feitos humanos como exemplos da capacidade humana em amenizar ou suprimir as influências do ambiente, esquecem-se de dar conta dos contrastes verificados entre culturas em termos de nível de desenvolvimento sócio-econômico. Para Heffernan, entre os pensadores iluministas, "Many were convinced that external environment exerted a pervasive influence and that human development was ultimately limited, whether by god, nature or both." (ibid, p. 134)

Ao trazer a discussão de Turgot sobre Montesquieu, Heffernan entende que 
Turgot was convinced by Montesquieu's socioeconomic materialism but was repelled by his environmental materialism, the latter running counter to a Lockean position on the potential of the human mind. In an important 'digression on climate', Turgot attacked the notion that a region's climate determines the nature of its human inhabitants, insisting on the 'need to have exhausted all moral causes before asserting the physical influence of climate'. (ibid, p. 130)

A questão que deve ser colocada aqui é quantos séculos, se que é possível, seriam necessários para se esgotar todas as causas morais para se entender as diferenças entre os homens. Estão em questão duas hipóteses, uma que advoga causas ambientais, e outra que busca causas morais, e uma não precisa ser inteiramente estudada, para que se possa finalmente esmiuçar a outra, posto que são ambas complementares, necessárias, e fazem parte de qualquer relação homem-meio que se queira melhor compreender. Isso denota certa pretensão em priorizar o estudo de um fator até esgotá-lo (impossível esgotar o estudo de um fator amplo como a natureza), fazendo vistas grossas ao outro fator, tratado como uma "sobra em caso de emergência".

Ao rejeitar os métodos e conclusões de Montesquieu, Heffernan afirma que Volney

(...) dismissed all forms of environmental determinism with simple historical and geographical observations: if climate and environment were determining factors, how could a single region (The middle East) experience such dramatically changed fortunes over recorded history with no evidence of comparable environmental transformations? And how could regions with similar environments in the present exist in so many different economic, social, political, and moral circunstances? (ibid, p. 138)

Na mesma direção, a de trazer falsas objeções que não resolvem o problema, Heffernan relata que

As to Montesquieu's 'axiom [termo usado para denotar rigidez e dogmatismo de pensamento]... that inhabitants of hot countries must necessarily be indolent, inert of body; and from as analogy, likewise inert in mind and body...and hence unable to resist despotic government', Volney offered a radical political alternative. Inertia and laziness were not caused by climate but by the possession of excess wealth: 'it is not as inhabitants of hot, but as inhabitants of rich countries that nations are inclined to indulgence' (ibid, p. 138)

Aqui se tem uma resposta evasiva que cria uma outra questão, cuja resposta é complexa e polêmica: o que leva um país a ter "excesso de riqueza"? Naqueles tempos, não seriam também os fatores ambientais (elementos naturais) importantes fatores a gerar riqueza em uma nação? O clima não favorece a abundância de flora e fauna? Ou seja, dizer que é o excesso de riqueza, e não o clima quente, que favorece a preguiça, é, indiretamente, continuar a defender o argumento ambientalista/determinista. Montesquieu reconhece também que em países nos quais a natureza é muito dadivosa e exuberante, as pessoas não serão impulsionadas ao trabalho, à criatividade e à batalha. 
Sem se dar conta da fragilidade da dualidade determinismo/possibilismo, Heffernan insiste que "Yet without an environmental causation, how could one explain the 'decline' of the civilizations of the middle east? The reasons, he claimed, were 'more general and compelling that the nature of the soil or the climate: they lie in the various social institutions which we call government and religion" Autores deterministas reconhecem a complexidade dos fenômenos que estudam, e reconhecem que as influências ambientais estão sempre presentes, em todos os lugares e em todos os tempos. Huntington reconheceu o papel da hereditariedade, Montesquieu, da religião, Comte, um dos mais pensadores mais surrados pela crítica, reconhece a ação política como um importante fator, isso só para citar alguns exemplos dentre uma interminável lista. Nenhum deles foi determinista a ponto de enfatizar apenas o clima e demais fatores geográficos.

Heffernan discute a ideia da ambivalência na obra de Saint-Simon e suas explicações servem de ótimo exemplo do problema do rótulo e da simplificação de autores. Assim, sobre Saint-Simon diz: "His philosophy has been variously interpreted as utopian socialism, radical bourgeois conservatism, and a forerunner of modern totalitarianism. The ambivalence is neatly summed up by Eric Hobsbawn: Saint-Simonianism 'can be assigned neither to capitalism nor to socialism, because it can be claimed by both." Esses qualificativos atribuídos a Saint-Simon, se tomados isoladamente, são apenas uma das facetas do autor, e até mesmo podem não passar de equívocos ou leituras tendenciosas. Assim como tanto o capitalismo quanto o socialismo podem invocar uma relação com o Saint-Simonianism, mesmo sendo contraditórios em suas propostas de sociedade, tanto teorias racistas quanto anti-racistas podem alegar uma íntima relação com o determinismo ambiental.

Spate também traz colaboração essencial para a desmistifiação da famosa dualidade. Mostrou o determinismo no possibilista Toynbee, e o possibilismo no determinista Huntington, e conclui afirmando que:

So far I have examined, in what may seem an unduly critical spirit, two antithetic philosophies of history which have yet a common significant character in that they both seek to establish a pattern and so are broadly determinist. Toynbee, on the whole at least, may seek to minimize, Hunting-ton to stress, physical factors; yet even here they are but two sides of the same coin. The link between them I think is this: that however much they differ as to the role of environment, they both fall into the fallacy that there is or can be such a thing as environment "taken by itself". (SPATE, 1952, p. 418-419)

Spate (1974) também esclarece que na década de 50 havia muitas reações contra o possibilismo. Esses textos evitavam a rudeza do primitivo conceito de controle do meio, assim como negava o beco sem saída do possibilismo, acentuando qualquer situação que 
girasse em torno da probabilidade, como tantas vezes fizeram, sem admitir, deterministas e possibilistas. Nesses autores nota-se que o ambiente físico não é mais do que uma parte do ambiente total e que as atividades humanas introduzem nele modificações. As influências ambientais atuam através da sociedade e a tradição cultural tem certos efeitos autônomos e recíprocos. Evita o dogmatismo ao mesmo tempo em que sustenta que há um mínimo irredutível de influência do ambiente.

Quanto ao probabilismo, já foi conceituado como a teoria intermediária entre determinismo e possibilismo, e sobre ele, Martin explica que é similar ao possibilismo e que também é autocontraditório:

Probabilism. Professor O. H. K. Spate has recently (in a paper entitled 'Toynbee and Huntington: a study in determinism, Geographical Journal, 118 (1952), 406-28 proposed to replace Possibilism by a doctrine of Probabilism. This would differ from Possibilism in postulating that while the environment provides a number of possibilities between which man is to choose, some among these possibilities are more probable than others. The most probable of these possibilities would presumably be that which is easiest, as it were, for man to follow, while to follow any of the other less probable courses a progressively greater effort of will would be needed. As a logical basis for a scientific human geography Probabilism differs little from Possibilism, for it maintains that human phenomena are in part determined (in order to decide the order of probabilities) and in part not (in order to allow man to choose between them). The position, as has already been shown, is self contradictory. As an empirical account of the situation as we apprehend it when decisions are made it is debatable whether Probabilism is any improvement on Possibilism (see note c). Possibilism seems to give a better subjective account of the situation of making up one's mind or of advising someone who is doing so. Probabilism seems appropriate when we are, as we often are in geography, objectively and dispassionately considering the choices of other people. To judge from his paper Professor Spate appears to be a practising determinist, and that is, in effect, as much as this paper is contending for. (MARTIN, 1952, p. 11)

Spate afirma que há uma maré da opinião geográfica (que nós chamaríamos de "palpiteiros ideológicos" contra a possibilidade de compatibilizar o determinismo com a ideia de que não existe ambiente sem homem (ambiente per se). Assim aponta que:

The danger is in setting up a false duality and so involving ourselves in insoluble or unnecessary questions of the chicken-and-egg order. There is also the danger, shared by possibilist and determinist alike, of anthropo-morphizing Nature; those who talk glibly of 'cooperation with Nature's plan' do not often face up to the teleological implications of this phrase. Insistence that there is no human environment without man is not in itself incompatible with the strictest determinism of physical controls. It is not necessary to demonstrate formally the error of that view; it is patent in our examination so far, and indeed the tide of geographical opinion is still running strongly against it. Perhaps too strongly, since it does not seem certain that 'possibilism' as often understood (or misunderstood) is the automatic alternative to a rigorous environmentalism. There may be a middle term, which one might call 'probabilism'; nor do I think that more than this is really implied by the original French masters, Vidal de la Blache and the rest. It must be remembered that they worked in an atmosphere steeped 
in precise methodological thought; English empiricism and American pragmatism may sometimes miss its undertones. Let us take Febvre's famous assertion 'there are no necessities but everywhere possibilities. [Essa frase é a mais recortada e espalhada da obra de Febvre, assim como Semple também tem a sua "frase-estigma"] I agree with what I take to be the meaning of this sentence; yet there are times when I feel that no single dictum has had a more disastrous influence on modern geographical thought and work. There could be no confusion if Febvre had added 'of which some are more possible than others'; probabilities, that is, rather than a vague assortment of free choices. Febvre himself mentions the negative necessity of not trying to grow pineapples in Greenland, and the much more important matter of commitment by one's choice: 'all possibilities are not copossibilities.' Clearly he did not mean to say that any possibility is present anywhere at any time, and Tatham is right in pointing out that sniping at possibilism on the pineapples-in- Greenland line is futile. Put so bluntly this is a truism; but in practice the emphasis on human initiative, correct in itself, has sometimes been given its head and has landed in thinking which is as intolerably woolly and vague as rigorous environmentalism is intolerably narrow and crude. (ibid, p. 419-420)

Com esse artigo, Spate toca em sua teoria probabilista, por ele lançada no universo geográfico. O probabilismo não despertou as famigeradas críticas lançadas aos deterministas, mas não imperou incólume, pois nenhuma teoria jamais alcançou esse status em ciências humanas. As críticas à Febvre são um tanto partidárias, dada a animosidade histórica entre franceses e ingleses, principalmente no plano das ideias, mas Spate supera partidarismos ao reconhecer que Febvre, na verdade, não acredita num infinito rol de possibilidades, logo, como ele, advoga o probabilismo. Aliás, de nossas leituras, ficou a impressão de que todos os autores, "desde a idade da pedra lascada", sempre falaram em probabilidade ou em algo próximo a isso. Essa dualidade determinismo/possibilismo parece ter como melhor finalidade propiciar lazer retórico-dialético-sarcástico, para uns, e temas para teses de doutorado, para outros.

Segundo os Sprout, havia duas tendências dentre os geógrafos com respeito ao possibilismo:

1. That the vogue of possibilism divided geographers over the issue of weather choices and decisions were their proper concern at all, and (2) that most geographers in their empirical work, felt a need for some escape from the narrow confines of possibilism. Many resolved this felt need by explaining and predicting choices by means of (generally implicit) assumptions of normally expectable behavior in the milieu under consideration. This seems to us the essence of Spate's idea of probabilism. (SPROUT, 1950, p. 43)

Os Sprout afirmam que um dos motivos para rejeição do possibilismo e a subsequente adoção do probabilismo é a incapacidade do possibilismo em explicar decisões e escolhas. O modelo comportamental do probabilismo permitiu entender melhor essa questão. 


\section{CONSIDERAÇÕES FINAIS}

A histórica do pensamento geográfico pode ser recontada superando-se o seguinte mito: "Ao determinismo ambiental contrapõe-se o possibilismo, ambos formando os polos opostos de um espectro dicotômico que vai da determinação fatal do ambiente e consequente falta de arbítrio humano, à passividade do ambiente e plena deliberação humana ancorada numa tudo-é-possível liberdade e numa autonomia ilimitada que dispõem de técnicas milagrosas para superar qualquer obstáculo imposto pelo meio físico”.

Contrapondo-se a este mito, o verdadeiro fato que foi possível levantar a partir da pesquisa e das leituras foi que o possibilismo não se constitui numa antítese do determinismo ambiental e não existe tal dicotomia, determinismo/possibilismo, senão nas ideias de intelectuais que pecaram por uma releitura simplista e tendenciosa de autores "deterministas" como Ratzel, Semple, Huntington, e de autores "possibilistas" como La Blache, Brunhes e Le Febvre. O possibilismo, pelo contrário, reforçou o importante papel das influências ambientais a tal ponto, que levou Franz Boas a rotular Vidal de La Blache de "determinista". É importante esclarecer que se a dualidade "determinismo/possibilismo" não sobrevive a uma análise mais aprofundada, essa mesma dualidade evolui a partir de um antagonismo bem mais real e claro, aquele que é notado por Boas já em 1880, entre a antropogeografia positivista e a antropogeografia historicista. Acrescentando, o determinismo ambiental em geral nunca negou a liberdade humana e sua capacidade de adaptação e transformação da natureza e apenas nos casos mais extremados pré-Ratzel, é que os deterministas formularam explicações apressadas sem algum suporte de evidências. Por seu turno, o possibilismo jamais deixou de reconhecer que o ambiente pode oferece obstáculos de uma importância tal, que chega ao ponto de restringir ao mínimo o número de opções disponíveis para essa sociedade na busca de seu desenvolvimento, e raramente negou que a natureza não pudesse impedir por completo determinadas atividades e escolhas humanas.

Tanto possibilistas quanto deterministas sustentavam que um rol cada vez mais amplo de possibilidades estaria disponível ao homem à medida que seus conhecimentos avançassem, mas que se tornariam menos amplos a partir de certo ponto de saturação dos sistemas naturais. Alguns ecologistas e profissionais afins poderiam concordar com a previsão de que o rol de possibilidades atingirá um máximo e que após esse momento, com o exaurimento dos recursos, será cada vez menor, levando a civilização ao seu ocaso ou colocando-a num patamar constante de poucas possibilidades num mundo marcado por crescente dependência dos humanos, tanto em relação às suas técnicas sustentadas, quanto aos escassos recursos. 
Na história do pensamento geográfico o possibilismo esvaziou-se de sentido e o determinismo foi declarado morto, entrando em cena o probabilismo, formulado na Geografia por Spate. Segundo essa "nova-velha” teoria, em última instância, a natureza torna algumas escolhas humanas mais viáveis do que outras, de modo que alguns padrões se fazem mais prováveis do que outros. O probabilismo parece ter sido a última "teoria" ou proposta a lidar com o problema das influências ambientais, e depois dele, nada mais foi proposto na feira geográfica das teorias e especulações, em torno da ideia das influências ambientais. Em não havendo mais discussões sérias acerca de um tema tão fundamental da Geografia e da ciência, mitos, fantasias, dúvidas e inseguranças foram fermentando no coração da história do pensamento geográfico, prestes a explodir aurículos, ventrículos, veia cava e aorta, tudo junto, e sem direito a pontes de safena ou transplantes.

Sobre a referida dualidade, esta foi se esvaindo conforme mais e mais autores eram “invertidos” em seus rótulos. Assim, La Blache e Brunhes foram agrupados por Boas sob o mesmo rótulo que Ratzel (determinista), assim como Montesquieu, tão rotulado de determinista, foi considerado "geógrafo possibilista" por Kriesel. Conforme a crítica sagaz foi argumentando mais e mais em prol de um abandono desse binômio insustentável, mais essa gelatina bicolor e indigesta se liquefazia. A dualidade determinismo/possibilismo representou uma divertida maratona geográfica na qual cada um dos times agarrava-se às suas crenças e atribuíam a seus adversários um suposto hasteamento da bandeira radical de suas teorias, cada bandeira representando um pólo extremo dos espectros idealizados e metafisicamente especulativos, ou seja, uma visão impossível e descabida que ou reconhecia a total liberdade do gênio humano em "domar" a natureza, ou reconhecia a total tirania fatalista da natureza.

Olhando para as minúcias dos discursos, notou-se, pelo contrário, que nenhum dos lados foi capaz de negar os principais argumentos do adversário, pois houve apenas algumas diferenças na ênfase dada, e principalmente, na retórica. Na verdade a ênfase não foi tão distinta, a real diferença esteve no espaço e empenho dedicados a cada um dos fatores (ambientais/físicos \& humanos). Assim, deterministas esmiuçaram os fatores ambientais em primeiro plano, enquanto possibilistas enfatizavam a capacidade de adaptação humana e as forças da tecnologia para amenizar os impactos dos fatores ambientais e aumentar o número de possibilidades oferecidas pela natureza. Ambos reconheciam a liberdade humana com igual ênfase, muito embora os deterministas, em suas retóricas, ora desastradas ou apenas mal compreendidas, fossem acusados de propor uma relação extremamente desigual, com uma natureza ativa e tirana exercendo influência impiedosa sobre uma sociedade passiva e um homem débil. 
A história do pensamento geográfico precisa se libertar de dogmas, de desfiles de pais e avós da Geografia, de rótulos pesados, do paradigmocentrismo, da possessão noológica, de estereótipos empobrecedores, de recortes tendenciosos, da falta de leitura completa dos originais, da comparação precipitada, da interpretação parcial, do comodismo em repetir bordões e slogans, do pernicioso telefone-sem-fio das ideias, enfim, das falsas dualidades que se nutrem de todos esses supracitados "pecados capitais" da pesquisa em história das ideias. O ensino da Geografia, principalmente nos cursos de graduação, tem sofrido com esses vícios do pensamento, e é preciso mais atenção da comunidade geográfica quanto ao estudo da história do pensamento geográfico, e um cuidado especial com a compreensão da complexa natureza da relação sociedade-meio físico, e que reconhecer como fundamental as influências do meio físico sobre a sociedade é um caminho prudente no contexto do desenvolvimento sócio-econômico, da qualidade de vida e da saúde ambiental do planeta.

\section{REFERÊNCIAS}

1. ABBAGNANO, N. Dicionário de Filosofia. São Paulo: Martins Fontes, 2007.

2. BOAS, F. Anthropology and Modern Life. New York: Dover Publications, Inc, 1986.

3. BRUNHES, J. Geografia Humana. Rio de Janeiro: Editora Fundo de Cultura, 1962.

4. DIAMOND, J. Armas, Germes e Aço. São Paulo: Editora Record, 2007.

5. C__ Colapso: Como as sociedades escolhem o fracasso ou o sucesso. Rio de Janeiro: Record, 2009.

6. FEBVRE, L. A Geographical Introduction to History. London: Routledge \& Kegan Paulk Ltd, 1925.

7. Panorama da Geografia. Vol. III. La Tierra e la Evolution Humana. Introducción geográfica a la Historia. Barcelona: Editorial Cervantes, 1925.

8. FREEMAN, T.W. A Hundred Years of Geography. London: Gerald Duckworth \& CO. LTD, 1961.

9. GAILE, G.L.; WILLMOTT, C.J. Geography in America at the dawn of the 21st century. Oxford: Oxford University Press, 2003.

10. GARAVAGLIA, J.C. Human beings and the environment in america: On 'Determinism' and 'possibilism'. International social science journal. v. 44 n. 4, p. 569-577, 1992.

11. GLACKEN, C.J. Traces on the Rhodian Shore. Nature and Culture in Western thought from Ancient Times to the end of the Eighteenth Century. Berkeley and Los Angeles: University of California Press, 1967.

12. HARTSHORNE, R. "Exceptionalism in Geography" Re-Examined. Annals of the Association of American Geographers, v. 45, n. 3, p. 205-244, set., 1955. 
13. Propósitos e Natureza da Geografia. São Paulo: Hucitec, 1978.

14. HEFFERNAN, M. 1999: Historical geographies of the future: three perspectives from France, 1750-1825. In: Livingstone, D.N. and Withers, C.W.J., editors, Geography and enlightenment, Chicago: University of Chicago Press, p. 125-164.

15. HUNTINGTON, E. Civilization and Climate. New Haven: Yale University Press, 1939.

16. JARDIM DE CARVALHO JR, I. Os clássicos da climatologia geográfica: a contribuição pioneira de Ellsworth Huntington. Geousp. GEOUSP: espaço e tempo, n. 32, 2012.

17. . Ellen Semple e a paráfrase poética na obra "influences of the geographic environment". GEOSUL. v. 26, n. 52, 2011.

18. LA BLACHE. Princípios de Geografia Humana. Lisboa: Cosmos, 1946.

19. LALANDE, A. Vocabulário técnico e crítico da filosofia. São Paulo: Martins Fontes, 1999.

20. LEWTHWAITE, G. Environmentalism and determinism: a search for clarification. Annals of the association of american geographers. v. 56, n. 1, p. 1-23, mar., 1966.

21. _ The history of geography: review. The Geographical Journal, v. 136, n. 2, p. 253-255, jun., 1970.

22. MARTIN, A.F.: The necessity for determinism. Transactions, Institute of british geographers. n. 17, p. 1-12. 1955.

23. MONTEFIORI, A.C. WILLIAMS, W.C. Determinism and Possibilism. Geographical studies. v. 2, p. 1-11, 1955.

24. MONTESQUIEU. O Espírito das Leis. Brasília: Editora Universidade de Brasília, 1995.

25. MOREIRA, R. Para onde vai o pensamento geográfico? Por uma epistemologia crítica. São Paulo: Contexto, 2006.

26. PEET, R. The social origins of environmental determinism. Annals of the Association os American Geographers v. 75, n. 3, p. 309-33, 1985.

27. On "Geographical determinism in fin-de-siècle Marxism: georgii Plekhanov and the environmental basis of russian history" by Bassin. Annals of the association of American geographers, v. 83, n. 1, p. 156-160, mar., 1993.

28. PLATT, R.S. Environmentalism Versus Geography. The American Journal of Sociology, v. 53, n. 5, p. 351-358 mar., 1948.

29. SEMPLE, E. C. Influences of Geographic Environment on the Basis of Ratzel's System of Anthropo-Geography. New York: Henry Holt and Company, 1911.

30. SPATE, O.H.K. Toynbee and Huntington: A study in determinism. In: The Geographical Journal, v. 118, n. 4, p. 406-424. dez., 1952.

31. . “determinismo" Geográfico. In: Enciclopedia Internacional de las Ciencias Sociales. v. 3. Madri: Aguilar sa ediciones, 1974.

32. SPETH, W. The Anthropogeographic theory of Franz Boas. Anthropos, v. 73, 1978. 
33. SPROUT, $H$ and M. Man-milieu relationship hypotheses in the context of international politics. Princeton: center of international studies, Princeton University, 1950.

34. TATHAM, G. Environmentalism and Possibilism. In: TAYLOR, G. Geography in the twentieth century: a study of growth, fields, techniques, aims and trends. London, Methuen, 1951.

35. . Environmental Factors in the Study of International Politics. The Journal of Conflict Resolution, v. 1, n. 4, p. 309-328 dez., 1957.

36. TAYLOR, G. Geography in the twentieth century: a study of growth, fields, techniques, aims and trends. London, Methuen, 1945.

37. WILLIAMS, G. Free-Will and Determinism. The Journal of Philosophy, v. 38, n. 26, p. 701712, dez., 1941.

38. WALLIS, W.D. Geographical Environment and Culture. Social Forces, v. 4, n. 4, p. 702-708, jun., 1926.

39. Environmentalism. In: Encyclopeadia of the Social Sciences. v. 5. New York: The Macmillan Company, 1931.

ARTIGO RECEBIDO EM ABRIL DE 2017

ARTIGO APROVADO EM AGOSTO DE 2017 